\title{
Talamantes y su proyecto para la independencia de México y la creación de una comunidad de reinos hispánicos*
}

\author{
Juan Pablo Pampillo Baliño**
}

\section{INTRODUCCIÓN}

En la presente intervención me propongo, además de bosquejar el contexto, biografía, pensamiento y propuestas de Melchor de Talamantes, intentar revalorarlo como protagonista de su tiempo, así como también poner de relieve su legado y proyectos, como una inspiración de una acuciante actualidad para Perú, México y en general Latinoamérica. ${ }^{1}$

Lamentablemente, a más de dos siglos de distancia, Talamantes sigue siendo un gran desconocido entre nosotros y son todavía demasiado escuetas las pocas líneas que se le dedican en las obras generales de historia, a pesar de los esfuerzos emprendidos por muy pocos estudiosos para dar a conocer la importancia de su pensamiento y obra. $^{2}$

* Intervención principal dentro del Conversatorio "Fray Melchor de Talamantes, peruano precursor de la Independencia de México”, celebrado con motivo de su 210 aniversario luctuoso en la Secretaría de Relaciones de México, bajo los auspicios de dicha Secretaría, del Instituto Matías Romero y de la Embajada de Perú en México, el 10 de mayo de 2019.

** Escuela Libre de Derecho, Ciudad de México, México. Correo electrónico: juanpablopampillo@yahoo.com.mx. ORCID: https://orcid.org/0000-0002-3570-031X.

1 La presente intervención recoge sintéticamente los resultados de una amplia investigación histórica y archivística con motivo del bicentenario de la participación de Talamantes en el movimiento de 1808 cuyos resultados fueron recogidos en mi libro Pampillo, El primer constitucionalista de México. Talamantes: ideología y proyecto para la América Septentrional, passim.

2 En términos historiográficos únicamente cinco autores han investigado con profundidad a Talamantes y publicado semblanzas biográficas relativamente completas y confiables, en las cuales se han basado todas las demás existentes, así como las pocas líneas que se han recogido en las obras generales o especializadas en la coyuntura de 1808. Dichas semblanzas y autores son: el folleto publicado por el historiador mexicano Luis González Obregón en 1909, los artículos de la historiadora peruana Emilia Romero del Valle de 1944 y de 1961, los estudios de 1995 y de 2009 debidos al religioso mercedario peruano Mons. Severo Apa- 
Pero, ¿a qué se debe semejante abandono? Pudiera conjeturarse que a su procedencia extranjera; sin embargo, la realidad es que para entonces los reinos atlánticos formaban una misma patria con su metrópolis ibérica y nuestro personaje residió en Nueva España en las mismas condiciones que en Perú. Quienes quisieran explicar su olvido en razón de su estado religioso, no consideran que muchos de los principales ideólogos y próceres de nuestras gestas emancipadoras también pertenecieron a la Iglesia, comprometida en muchos casos con los ideales de libertad e igualdad que promovió Talamantes. Se ha aventurado también como causa de su postergación el que su pensamiento resultaba demasiado vanguardista, así como el que su participación en el debate institucional sostenido entre el Virrey, la Real Audiencia y el Ayuntamiento fue más bien indirecta. Sin embargo, aunque sus ideas fueron más audaces que las de sus contemporáneos, las presentó, hábilmente, arropadas bajo el prestigio de autores considerados como aceptables por la Inquisición y la Monarquía y las expuso en términos que hubieran permitido que nuestras Independencias no fueran el resultado de revoluciones sangrientas, sino de un acuerdo político benéfico para todas las partes involucradas. Además, a pesar de su participación indirecta, todos los protagonistas de la época, tanto partidarios como detractores, estaban conscientes de que él era el principal ideólogo detrás del partido criollo.

Quizás, suponiendo la concurrencia de factores más sutiles, su preterición obedezca a que no fue un exaltado de aires románticos como Francisco de Miranda, ni un político calculador como Agustín de Iturbide, ni un gran militar como Simón Bolívar, ni, en definitiva, alguien que pretendiera destacar por su radicalismo o con estridencias... sino sencillamente, una persona que quiso razonar y proponer un plan para consumar nuestra emancipación "sin efusión de sangres", del que pudieran emerger mejores gobiernos y formarse incluso una comunidad iberoamericana de naciones. ${ }^{3}$

En fin, algunas e incluso todas las anteriores circunstancias podrían explicar — que no justificar - el relativo olvido al que ha sido relegado, inclusive por los especialistas en los episodios de 1808, quienes en general no le han dedicado el espacio que merece.

ricio Quispe, y los artículos y ponencias del jurista peruano Teodoro Hampe-Martínez, el último de los cuales vio la luz en 2010. Finalmente se encuentra mi libro anteriormente citado, así como varios artículos, capítulos y ponencias, previas - desde 2007- y posteriores, a través de las cuales he procurado difundir la importancia de la persona y su pensamiento. Además de las anteriores obras y autores, destacan también las reseñas y bosquejos de Alarcón Bejarano, García Icazbalceta, Henriod de los Ríos, Ochoa Ventura y Puga y Acal, entre otras, si bien carecen de la exhaustividad de las semblanzas primeramente citadas. Se incluye la referencia puntual a los anteriores estudios en la bibliografía que aparece al final. 
Y sin embargo, nos encontramos ante el mejor formado y más sólidamente ilustrado e imaginativo de los precursores de nuestras Independencias; el único que tuvo el valor de plantear explícitamente la posibilidad de la emancipación en 1808 y el verdadero inspirador del partido mexicano, pues fue él quien originalmente planteó diversas medidas, entre las que destaca la instalación de un Congreso Nacional, que llaman la atención por su sensibilidad jurídica y política, por su realismo, por su certero diagnóstico de la situación y por su penetrante visión del porvenir, así como por su constante apelación a la fidelidad y amistad entre los reinos españoles y a la evitación del derramamiento de sangre.

Infortunadamente, el golpe de estado del partido peninsular deponiendo al Virrey Iturrigaray, canceló toda posibilidad de aprovechar la coyuntura de 1808, que bien pudo haberse convertido para Nueva España —y en general para las Indias - en una oportunidad privilegiada para sustituir — de manera ordenada y pacífica - los lazos del colonialismo por los vínculos de una comunidad de naciones hermanas.

Si el partido criollo hubiese tenido la misma resolución que tuvo el peninsular... si se le hubiera adelantado (¡como proponía Talamantes!)... quizás muy otra sería la historia de México y de Hispanoamérica...

En tal supuesto de 'historia contrafactual', el Padre Talamantes hubiera sido reconocido como el principal ideólogo de la independencia mexicana, como el verdadero 'padre de la patria', como su más profundo y adelantado pensador, como uno de los arquitectos del constitucionalismo americano e incluso universal y como precursor del para entonces inexistente "sueño bolivariano" que bien hubiera podido llamarse "ensoñación talamantina".

Pero el pasado se encuentra irrevocablemente cerrado y la historia sólo puede devolverle a Talamantes su recuerdo.

Por eso el ejercicio imaginativo de la historia contrafactual, pues nos ayuda en este caso [a] dimensionar el tamaño de nuestro protagonista más allá de sus circunstancias aciagas, a valorar su testimonio y a comprender mejor su proyecto y legado.

Testimonio, legado y proyecto que podrían sintetizarse en los siguientes aspectos: a) tratar de conciliar las ideas y los intereses aparentemente opuestos, mediante un ejercicio de búsqueda del entendimiento y la concordia, asumiendo una actitud pragmática superadora de todo dogmatismo radical, b) intentar armonizar en su presente nuestra tradición histórica y un proyecto de futuro sin regresiones ni rupturas, c) ser un extranjero en su patria, es decir, un peruano en la nación mexicana, que considera a las dos como partes de una misma 'patria grande', d) asumir una clara conciencia de que los vínculos culturales que unen a nuestros países les servirían para alcanzar una mejor posición en el contexto internacional, y e) participar, activa aunque 
indirectamente, como parte de la sociedad, en los asuntos y debates públicos, procurando incidir sobre los mismos.

Y me parece que dicho testimonio, legado y proyecto, nos sigue interpelando, con particular apremio, en el presente.

\section{Personalidad y Tiempos}

Si la existencia del hombre es —según Ortega y Gasset— la suma de "el yo" y "su circunstancia", vale la pena detenerse, aunque sea brevemente, en las particulares de nuestro personaje.

Melchor de Talamantes Salvador y Baeza nació el 10 de enero de 1765 en Lima, capital del Virreinato del Perú y murió —a los 44 años- el 9 de mayo de 1809, en la Cárcel de San Juan de Ulúa, en Veracruz. En números redondos, vivió sus primeros treinta y cinco años — hasta 1799— en Lima, la Ciudad de los Reyes y los diez restantes de su vida en la Ciudad de los Palacios, antes de su traslado póstumo a Veracruz.

El mundo que le tocó vivir, marcado hacia la segunda mitad del siglo XVIII por tiempos convulsos - y confusos- se debatió entre la pervivencia de tradiciones y el advenimiento de profundos cambios, jalonados por las nuevas fuerzas que habrían de marcar el porvenir, enfrentándose contra la dependencia, el colonialismo, la desigualdad y el clericalismo de la sociedad virreinal. Las ideas políticas de la Ilustración (Montesquieu, Rousseau, Voltaire, Mercier) y anticolonialistas de los economistas clásicos (Smith, Raynal, Robertson), la Independencia de los Estados Unidos en 1776 y la Revolución Francesa en 1789, ejercieron una poderosa influencia sobre las clases ilustradas.

A su vez, el descontento que trajeron consigo varias de las reformas ilustradas de los Borbones, especialmente la expulsión de la Compañía de Jesús en 1767, así como diversas exacciones para financiar las guerras de España en Europa, aunado a una conciencia cada vez más madura sobre la propia identidad, incubaron una serie de inquietudes que encontraron un cauce apropiado de expresión con motivo de la invasión napoleónica, la abdicación y secuestro de la familia real y la imposición de José Bonaparte como Rey en 1808.

Fue una época de tensión, de crisis, de cambios (la de Talamantes, como también la nuestra), de inercias del pasado y anticipaciones de un futuro pendiente de construirse, que nuestro personaje supo enfrentar — como muy pocos, entonces y ahora - con la prudencia y la moderación que media entre la tradición y la modernidad, entre lo viejo y lo nuevo, entre la pretendida validez de una sola perspectiva y el supuesto idéntico valor de todas, que acaba por deteriorar el mérito propio de cada una. 
Dentro del anterior contexto histórico, Talamantes fue educado desde los diez años por el fraile mercedario Manuel de Alcocer tomando a los quince el hábito de la Orden de Nuestra Señora de las Mercedes, cuya espiritualidad desde sus orígenes estuvo caracterizada por el valor de la libertad.

La inclinación que Talamantes mostró desde entonces por el estudio, la libertad con la que completó sus lecturas religiosas, enriqueciéndolas con muchas prohibidas por el Santo Oficio, así como su temperamento, la mayor parte del tiempo religioso y obediente, pero también, por momentos, digno y hasta altivo — rebelde según algunos—, nos hacen pensar — como en otros casos- la existencia de una vocación intelectual que acompaña a otra vocación religiosa.

Lo cierto es que sus estudios dentro de la Merced se caracterizaron por una sólida formación gramática y lógica proporcionándole los instrumentos dialécticos que habrían de servirle como predicador primero y posteriormente, hacia los albores de la independencia, como promotor de la misma.

Terminados sus estudios medios en la Orden, prosiguió su carrera académica graduándose como doctor en teología por la Universidad de San Marcos, que en dicho siglo había prohijado a personajes tan ilustres como Pablo de Olavide, Vicente Morales Duárez, José Baquíjano y Carrillo, Camilo Henríquez e Hipólito Unanue, entre otros.

Sus estudios estuvieron marcados por la tensión entre la escolástica, ya en franca decadencia, las nuevas direcciones de la filosofía moderna y los múltiples intentos de conciliación entre las diferentes corrientes debidas a los polígrafos y eclécticos del siglo XVIII. En su paso por la Universidad obtuvo múltiples distinciones académicas que le acompañaron toda su vida, encumbrándolo en el mundo intelectual del Virreinato del Perú desde muy temprano. Incluso sabemos que a sus veintiocho años de edad fue llamado para manejar varios negocios —algunos de carácter reservado- del gobierno del Virrey Francisco de Gil y Lemus.

Durante los poco más de treinta años que Talamantes vivió en la Ciudad de Lima, conoció al connotado médico y profesor de la Universidad de San Marcos, el doctor Unanue, quien fue precursor de la independencia del Perú y uno de los firmantes de su Acta de Independencia, siendo también, posteriormente, ministro bajo los generales José de San Martín y Simón Bolívar.

Desafortunadamente, no tenemos mayores datos sobre la vida de Talamantes en Lima, por lo que sólo nos queda conjeturar fundadamente que sus relaciones en el palacio virreinal debieron permitirle el acceso a diversas lecturas, relaciones y conversaciones, que completaron su formación intelectual con las últimas ideas del liberalismo y de la ilustración, lo que muy probablemente motivó su viaje a Nueva España, ante la previsión —que posteriormente habría de materializarse - de que alguna búsqueda de la Inquisición pudiera apuntar en su dirección y pararle perjuicio. 
Así fue como Talamantes desembarcó en Acapulco en noviembre de 1799, pasando a hospedarse en el convento de la Merced. Su estancia en Nueva España — supuestamente provisional y en tránsito a la metrópoli ibérica - sugiere también que no debió haberle sido inconveniente la vida en su nueva residencia.

Como 'extranjero en su patria' sabemos que muy pronto encontró cierta cómoda libertad, pues no guardaba sino relativamente la clausura, dedicando largas horas al estudio y asistiendo a diferentes tertulias, literarias, filosóficas y políticas, Incluso a partir de mayo de 1807, se le permitió tomar en arrendamiento una casa próxima al convento para instalar un estudio que necesitaría con motivo de una comisión que le fue solicitada por el propio Virrey.

También y al poco tiempo de haberse establecido en México, ya encontramos a Talamantes figurando en actos públicos de relieve. Además es conocida su buena relación con el capellán del palacio virreinal, el reconocimiento y prestigio de que gozaba entre los síndicos del Ayuntamiento, su trato con Jacobo de Villaurrutia, oidor de la Real Audiencia y director del Diario de México — quien le nombró censor del mismo—, así como su participación en las tertulias de los marqueses de Guardiola y de Uluapa, en las de la intendenta de San Luis Potosí y en las del Marqués de San Juan de Rayas. Igualmente se encuentra documentada su correspondencia con el Virrey Iturrigaray. Los anteriores contactos con el mundo, con el siglo, con los protagonistas del medio político, económico, social e intelectual de su tiempo, le fueron precisamente útiles para que su pensamiento pudiera encontrar cauces de expresión y se tradujera — como lo hizo- en acciones concretas.

Para concluir con su biografía anterior a los acontecimientos de los que fue protagonista, únicamente resta mencionar que en 1807, el Virrey Iturrigaray lo nombró como "principal comisionado" para reunir y ordenar diversos documentos relativos a las Provincias Internas que hacían frontera con los Estados Unidos. El sentido de la comisión respondía a la necesidad de fijar los límites entre Texas y la Luisiana. La titánica empresa que Talamantes desarrolló a título honorífico le permitió reunir un vastísimo material, que ocuparía cinco volúmenes, donde abordó además de la cuestión relativa a los límites, el tema de los derechos de la corona española sobre dichos territorios. La monumental obra — que lamentablemente quedó truncaanticipaba ya los sucesos, que cuarenta años después, habrían de despojar al México Independiente de la mitad de su territorio. También pues, en este rubro, Talamantes dejó constancia de su perspicacia visionaria, que lamentablemente, no fue atendida. 


\section{LA COYUNTURA DE 1808}

Ahora bien, fue con motivo de la inquietud y el desasosiego que trajo consigo la noticia de la abdicación de los reyes de España en 1808, que fray Melchor empezó a desarrollar la notable labor intelectual y atrevida actividad política por la que hoy lo recordamos.

Dicho quehacer intelectual y político estuvo precedido de estudios y lecturas que afortunadamente conocemos bien, pues se encuentran documentados en el juicio que se instruyó en su contra, donde además de sus declaraciones, obra el inventario de su biblioteca y papeles. Además, dicha información se ha podido complementar con el legajo de un caso abierto por la Inquisición en Perú contra el barón de Nordenflicth, proporcionándonos una radiografía bastante completa de sus influencias filosóficas.

En vistas de lo anterior podemos afirmar documentadamente que los intereses de fray Melchor de Talamantes, además de los propios de su estado religioso, abarcan la literatura, los idiomas (griego, latín, francés, inglés y vasco), la historia, la política, la economía, la física, la geografía, la medicina, la moral y el derecho, lo que nos permite, en primer lugar, apreciar la variedad de sus intereses culturales y científicos. Adicionalmente y por lo que hace a su pensamiento filosófico-político-y-jurídico, se le debe ubicar dentro del contexto intelectual del pensamiento criollo (segunda escolástica + iusnaturalismo racionalista + ilustración), que en su caso desarrolló sobre una sólida formación teológica-moral, influida específicamente por la Escuela de Salamanca, pero basada también en el método escolástico y la filosofía perenne aristotélico-tomista. Pero además, nos encontramos ante un religioso familiarizado con el derecho romano, canónico y natural, así como con el derecho de indias. Por último, puede asegurarse que nuestro personaje se encuentra plenamente interiorizado con el pensamiento de la Ilustración en todas sus vertientes: a) literaria (Voltaire), b) utópica (Mercier) y c) políticoeconómica (Rousseau, Montesquieu, Smith, Robertson y Raynal).

Así las cosas, y a partir de las anteriores coordenadas intelectuales, desde el 14 de julio - en que llegaron las primeras informaciones - y hasta la deposición del virrey Iturrigaray y su propia detención el 16 de septiembre de 1808, Talamantes abandonó su comisión para el asunto de límites y algunos de sus deberes religiosos, para participar, activa -aunque subterráneamente- en la reflexión y discusión pública de los anteriores acontecimientos.

Durante los dos intensos meses en que fueron fluyendo las noticias sobre los hechos que se sucedían en la península -motín de Aranjuez, invasión francesa, abdicaciones de Bayona, levantamientos y formación de las diversas juntas gubernativas, como las de Sevilla y Oviedo- Talamantes se concentró en la delicada problemática que los mismos revestían. 
Tras meditar sobre el tema y consultar sus libros, papeles y notas, fray Melchor compartió sus puntos de vista en las diferentes tertulias a las que asistía, pero también en el Portal de Mercaderes, en la relojería de Blasio y con el fiscal de la Real Audiencia, Ambrosio Sagarzurrieta, así como con los munícipes del Ayuntamiento Juan Francisco de Azcárate y Francisco Primo de Verdad y Ramos. Asimismo, procuró hacer llegar por escrito sus planteamientos a varios Ayuntamientos Provinciales, al Gobernador Intendente de la Provincia de Nueva Galicia, al brigadier Roque Abarca y al propio Virrey Iturrigaray, conminando a todos a convocar con urgencia un Congreso Nacional.

Las ideas del padre Talamantes fueron bien conocidas y ejercieron una considerable influencia en sus interlocutores, a quienes les habrán parecido, según su temperamento e intereses, convincentes o temerarias, plausibles o peligrosas.

Cabe destacar que durante aquellos meses aciagos la opinión fue unánime en su condena a la invasión napoleónica, desconociendo la usurpación de la monarquía. Se dividió, sin embargo, en dos grupos respecto a la actitud que debía asumir el virreinato ante los referidos hechos.

De un lado, la facción de los peninsulares —arraigada en la Real Audiencia - consideraba que el gobierno de Nueva España debía proseguir sin alteración, manteniendo el status quo político, social y económico. Por el otro lado, el partido criollo — atrincherado en el Ayuntamiento de la Ciudad de México - pensaba que ante la ausencia del rey era necesario formar una junta similar a las que se organizaron en la metrópoli, que reasumiera la soberanía durante la ausencia del monarca y que confirmase a las autoridades del reino. Por su parte, el virrey Iturrigaray, si bien simpatizaba con el partido criollo, asumió una actitud tímida y ambigua, aceptando por un lado las propuestas del Ayuntamiento, pero dando cabida también las objeciones de la Audiencia. Y fue precisamente su tibieza y falta de resolución lo que posibilitó que a la postre la facción peninsular se adelantara en deponerlo, sustituirlo por Pedro Garibay y aprehender a los principales simpatizantes del grupo americanista, incluidos el propio virrey, el regidor Azcárate, el síndico Primo de Verdad y desde luego, Melchor de Talamantes.

Dentro de las discusiones oficiales que se efectuaron - sesiones de cabildo, de Real Acuerdo, y Juntas Generales convocadas por el Virreynuestro personaje intervino, indirecta aunque activamente, intercambiando perspectivas con varios de los protagonistas y circulando entre ellos algunos escritos suyos, entre los que destacan dos que revisten la mayor importancia: el Congreso Nacional del Reino de la Nueva España y la Representación Nacional de las Colonias. Discurso Filosófico.

Para entender mejor la importancia de los debates que se produjeron en 1808, hay que destacar que éstos versaron sobre la manera de organizar el 
gobierno ante la invasión francesa, refiriéndose por ello a la delicada y fundamental cuestión de la soberanía, como piedra angular del pensamiento político moderno-contemporáneo, que vertebra los conceptos de poder, constitución, nación, pueblo y gobierno.

En efecto, la cuestión de la soberanía debía abordarse en tres de sus principales proyecciones: el origen del poder, su sede natural y el depositario del mismo, en razón del problema suscitado por la inesperada desaparición de su detentatario habitual dentro de la organización política española: el rey.

Pero la necesaria reflexión sobre dichas cuestiones podía conducir - y de hecho condujo - a planteamientos peligrosos desde el punto de vista de una equivocada ortodoxia religiosa y de una ideología política eminentemente colonialista. En efecto, el origen del poder podía referirse al monarca o a Dios, pero también al pueblo. Su sede natural podía estar en el rey, pero también en la nación o en la constitución. Y, por supuesto, de referirse al pueblo, se estaría legitimando la posibilidad de que el mismo, soberanamente, optase por darse una nueva constitución o, inclusive, decidiera reclamar el derecho a su propia independencia.

La crisis de la monarquía dio lugar así a la proliferación de escritos que fueron gestando un nuevo pensamiento que postuló ideas, valores y proyectos que habrían de convertirse en la levadura que fermentaría el pensamiento independentista y republicano en América y la Constitución liberal de Cádiz de 1812 en España.

Ahora bien, un interesante aspecto a poner de relieve sobre el pensamiento de Talamantes es que se advierte su pragmatismo y eclecticismo, procurando escoger los argumentos y autoridades menos sospechosos, que pudieran presentarse sin merecer anatemas religiosos o condenas por infidelidad al rey, aunque en realidad estuvieran inspirados en fuentes y pensadores abiertamente anticoloniales, liberales y soberanistas, proscritos tanto por la Iglesia como por la Monarquía.

De ahí que uno de sus principales méritos haya sido el buscar equilibrar su deber religioso de obediencia y comprometer su propia conciencia a pesar de las amenazas jurídicas inquisitoriales, tratando de articular analógicamente un pensamiento nuevo, sobreponiéndose al escrúpulo de la lectura de ciertas obras (consideradas ateístas, tolerantistas, e inmorales), tratando de encontrar en ellas, más allá de la personalidad de sus autores, de su contexto y de su mismo trasfondo filosófico, ideas que aportasen perspectivas que de alguna manera pensaba que podían encajar dentro de la ortodoxia de la Iglesia.

El pensamiento de Talamantes constituyó el primer paso hacia la emancipación y lo más significativo del mismo fue que dicho primer paso quiso darse como un avance, hasta cierto punto natural -aunque forzado por las 
circunstancias del caso, pero sin rupturas - a través los cauces institucionales, innovando sobre los principios políticos y jurídicos tradicionales, e intentando conciliar la fidelidad a la metrópoli y a su rey junto con el reconocimiento de la soberanía de los reinos ultramarinos.

En efecto, Talamantes buscaba que fueran las propias autoridades constituidas, el Virrey, la Audiencia y el Ayuntamiento, las que convocasen a un Congreso General que asumiera la soberanía en ausencia del monarca, intentando realizar así, por una vía institucional y legal, el primer paso hacia nuestra Independencia y, después, hacia la configuración de una Comunidad Hispana de Naciones.

Para ello, en sus Advertencias Reservadas, no deja lugar a dudas respecto de su interpretación de la situación y el destino final de sus planteamientos: "aproximándose ya el tiempo de la independencia de este reino, debe procurarse que el congreso que se forme lleve en sí mismo, sin que pueda percibirse de los inadvertidos, las semillas de esa independencia sólida, durable y que pueda sostenerse sin dificultad y sin efusión de sangres”. Pero, aunque el planteamiento independentista es inequívoco, también lo es el llamado a la prudencia, pues la emancipación debe procurarse precisamente "sin que pueda percibirse de los inadvertidos", es decir, sin bombo y platillo, hasta que pueda asegurarse de manera "sólida [y] durable" y, sobre todo, "sin efusión de sangres.

A partir de la anterior premisa, escribió y circuló su Representación Nacional, que es un ensayo filosófico-político para fundamentar la legitimidad de convocar a un Congreso General.

Dicho discurso fue dividido en dos partes. En la primera, de índole más general, definió la naturaleza de las colonias, de las leyes coloniales y regionales y de la representación nacional, que es la expresión con la que Talamantes se refería al concepto de soberanía. En la segunda, se exponen aquellos casos en los cuales se considera que es lícito a las colonias separarse de su metrópoli. Su conclusión, que anticipa sin rodeos desde la primera parte de su discurso, es inequívoca:

Desde el punto mismo en que se nos hizo saber que los reinos de España se habían cedido a una potencia extranjera... se han roto del todo para nosotros los vínculos con la metrópoli; las leyes coloniales que nos unían a ella y nos tenían dependientes han cesado enteramente, y no subsisten para dirigirnos sino las leyes puramente regionales (...) quedan [pues] estos reinos independientes de su matriz.

En la segunda parte, la más importante y sugerente de su notable discurso, Talamantes enunció y expuso los casos en los que les sería lícito a las colonias separarse de sus metrópolis. Dichos casos, según su parecer, eran: 
1) Cuando las colonias se bastan a sí mismas,

2) Cuando las colonias son iguales o más poderosas que sus metrópolis,

3) Cuando las colonias difícilmente pueden ser gobernadas por sus metrópolis,

4) Cuando el simple gobierno de la metrópoli es incompatible con el bien general de las colonias,

5) Cuando las metrópolis son opresoras de sus colonias,

6) Cuando la metrópoli ha adoptado otra constitución política,

7) Cuando las primeras provincias que forman el cuerpo principal de la metrópoli se hacen entre sí independientes,

8) Cuando la metrópoli se sometiera voluntariamente a una dominación extranjera,

9) Cuando la metrópoli fuese subyugada por otra nación,

10) Cuando la metrópoli ha mudado de religión,

11) Cuando amenaza en la metrópoli mutación en el sistema religioso y

12) Cuando la separación de la metrópoli es exigida por el clamor general de los habitantes de la colonia.

Conviene destacar que todos los anteriores casos eran vigentes en la coyuntura de 1808 y también constituyen un contrapunto argumental que realiza en sentido inverso, pero siguiendo el mismo método escolástico, a los ‘justos títulos’ propuestos por F. de Vitoria en sus Reelecciones para fundamentar en su momento la conquista.

Por lo que hace a su otro manuscrito principal, el Congreso Nacional del Reino de Nueva España, que partía de la premisa de la representación nacional o soberanía política como su fundamento, Talamantes se dedicó a exponer los motivos que recomendaban la convocatoria de una asamblea como cauce jurídico e institucional más adecuado. Por ello mismo, el Congreso Nacional fue un auténtico proyecto de organización constitucional, pues trata sobre las razones que aconsejan la instalación de un parlamento soberano, así como sobre la forma en la que debiera convocarse, integrarse y funcionar, desarrollando los mismos asuntos sobre los que debiera ocuparse y llegando a incluir, como corolario del mismo, la conveniencia misma de una comunidad entre los reinos hispanos de ultramar.

Lamentablemente, el golpe asestado por el partido peninsular el 15 de septiembre (iparadójica fecha!), impidió que los acontecimientos por venir pudieran fluir por los derroteros del orden y la legalidad. Se estableció así, absurdamente, un dique que forzaba a su necesario desbordamiento y fractura. Se cerraba, en definitiva, cualquier vía diferente de la rebelión armada para poder iniciar la Independencia. 


\section{PRISIÓN, JUICIOY CONDENA}

Visto como destacado representante del grupo americanista, como "el mentor de Iturrigaray" según Gabriel de Yermo, Talamantes fue aprehendido la madrugada del día 16 de septiembre.

La causa que se formó en su contra fue instruida —en virtud de su condición religiosa- por dos jueces como representantes de las jurisdicciones real y eclesiástica respectivamente. Durante los meses de septiembre y octubre, el padre Talamantes fue interrogado en varias ocasiones. Le fueron recogidos e inventariados sus libros, papeles, muebles y enseres - tanto de su celda conventual cuanto del apartamento contiguo donde despachaba-, dando cuenta de su erudición y también de la modestia y sobriedad religiosa de su vida cotidiana. Asimismo, rindieron testimonio dentro de su procedimiento varios de sus hermanos religiosos mercedarios, así como diversas personalidades que fueron citadas dentro del mismo, como los regidores Azcárate y Luyando, el Marqués de Uluapa y el Marqués de Guardiola, entre otros.

Resulta llamativa, incluso impresionante, la serenidad que trasluce en sus declaraciones, su agilidad mental e inventiva, la dignidad —incluso la altivez - de su defensa y, desde luego, su fino sentido del humor por medio de la ironía. En efecto, acusado de haber difundido argumentos contrarios a la fidelidad que las colonias debían a su metrópoli y a su rey y que conducían por lo mismo a la independencia del virreinato. Talamantes se defendió —sagaz y hasta humorísticamente - aduciendo que los manuscritos que había preparado constituían la primera parte - a ser impugnada posteriormente - de una obra apologética que debería intitularse: "Lo que conviene a las Américas: estar siempre bajo la Dominación Española”. Incluso afirmó que si el anterior argumento no resultaba convincente a sus jueces, deberían concluir que su defensa de la independencia no fue "práctica y civil sino cuando mucho filosófica y especulativa”, debiendo imponérsele en todo caso un menor castigo, pues sus "ejercicios literarios” pertenecían al ámbito de su pensamiento y conciencia, lo que también lo convierte por ello en un mártir de la libertad de expresión.

Lo cierto es que desde el 8 de octubre de 1808 se le declaró culpable nada menos que de 120 cargos, condenándosele como "reo de: Haber turbado la tranquilidad pública induciendo a la independencia". Curiosamente, prosiguió todavía la instrucción de la causa y no fue sino hasta el 23 de marzo de 1809 que se resolvió que sus delitos daban lugar a proceder "a su pronto exterminio", aunque, considerando la deferencia debida a los clérigos y para prevenir mayores escándalos, se adoptó la decisión de que "sin otros trámites se remitieran a España el reo y su causa para que S.M. dispusiera lo que hallase por conveniente". La anterior propuesta de sentencia capital fue 
presentada, paradójicamente, por Pedro Fonte, quien años después, recibiría bajo palio, entonces en carácter de Arzobispo, a Agustín de Iturbide, mandando cantar un Te Deum, en acción de gracias, por la consumación de la Independencia.

El 10 de abril fray Melchor fue sacado de las cárceles de la Inquisición para ser conducido a Veracruz, siendo encerrado en una de las estrechas 'tinajas' de la temible fortaleza San Juan de Ulúa, una de aquéllas más húmedas e insalubres que se encontraban bajo el nivel del mar. Por aquéllos días, la peste de la fiebre amarilla se había esparcido en la fortaleza. A los pocos días, Talamantes se contagió de dicha peste, complicándosele con vómito prieto. Murió el 9 de mayo, siendo enterrado en el cementerio de la Puntilla.

Poco antes de morir, en su calabozo, Talamantes escribió los siguientes versos según la popular forma de la décima espinela:

Dios amable que me tienes

en cárcel dura encerrado.

$\mathrm{Y}$ de un golpe me has privado

de mi honor, quietud y bienes.

Tú, mi Dios, que me sostienes

en tan triste situación,

ten ya de mí compasión

ablandando tus rigores,

y válganme los dolores

de tu infinita pasión.

Carezco en mi desconsuelo

de la protección humana.

y es mi diligencia vana,

si al favor del hombre apelo.

A tu trono, pues, el vuelo

dirige mi alma afligida.

La bondad, mi Dios, convida

a este exceso de confianza.

Haz, pues, feliz mi esperanza,

que de ti sólo está ávida

$\mathrm{Y}$, tras la muerte, un vago recuerdo - al que hoy contribuimos- y en general el abandono, aunque todavía queda la esperanza pendiente de rescatar su legado y sus proyectos. 


\section{TESTIMONIO, LEGADO Y PROYECTO}

Como se expuso desde el principio, el legado de Talamantes, de indudable actualidad, se encuentran en: a) tratar de conciliar las ideas y los intereses mediante la búsqueda del entendimiento y la concordia, asumiendo una actitud pragmática superadora de todo dogmatismo, b) su intento de armonizar en su presente nuestra tradición histórica y un proyecto de futuro sin regresiones ni rupturas c) ser un extranjero en su patria grande, d) su conciencia de los vínculos culturales que unen a nuestros países y les facilitarían una mejor posición en el contexto internacional, y e) su activa intervención, como parte de la sociedad, en los asuntos y debates públicos.

Así pues, por lo que hace a la conciliación entre la supuesta validez de una sola perspectiva y el pretendido idéntico valor de todas, así como al planteamiento atemperado de las ideas sin radicalismos excluyentes, Talamantes nos propone algo tan antiguo como el dialogos griego, que resurgió durante el medioevo a través del sic et non y del método escolástico hasta llegar a la coincidentia oppositorum, que retomó a su modo Hegel con su peculiar dialéctica, adoptó Unamuno como un llamado a la reconciliación española a través de su concepto de alterutralidad y que ha replanteado más recientemente Beuchot a través de su 'hermenéutica analógica'. Dicho método de contrastación, moderación y armonización resulta particularmente urgente en el debate contemporáneo, donde las corrientes económicas y políticas frecuentemente se nos presentan como ideologías irreconciliables a ser impuestas a cualquier costo. Y también resulta necesario como ejercicio prudencial entre lo viejo y lo nuevo, entre la tradición y la actualidad, con el propósito de construir un futuro que parta de la asimilación de nuestra historia y de nuestro presente.

$\mathrm{Y}$ es que las historias latinoamericanas se nos muestran como una constante búsqueda de la identidad, vocación y destino de nuestros pueblos, enfrentados en las contradicciones de cada época por las inercias tradicionales y las anticipaciones de un porvenir, que según las penetrantes expresiones de Leopoldo Zea, se traducen en que "nuestro pasado no se hace historia" y el "futuro no termina de hacerse presente".

En parte, porque el dinamismo de nuestras historias - como observara Octavio Paz sobre la particular de México- se ha desenvuelto según la lógica perversa de la "ruptura y el cambio", contrastante con el pragmatismo 'tradicional-proyectivo', 'reformador-continuista', de pueblos más afortunados que los nuestros, como característicamente la Roma Antigua, la Gran Bretaña y los Estados Unidos decimonónicos o la actual Unión Europea.

Nuestras independencias fueron así, en su mayor parte, guerras civiles fratricidas, que además degeneraron en disputas locales que acabaron por fragmentar a México, Centroamérica, la Gran Colombia y las Provincias 
Unidas. Y a las mismas siguieron las interminables pugnas entre monarquistas y republicanos, centralistas y federalistas, confesionales y laicos, liberales y conservadores, que marcaron el siglo XIX con sus permanentes disputas, prolongándose en muchas partes a lo largo del siglo XX y en algunos casos hasta el siglo XXI, a través de una sucesión de revueltas, dictaduras, revoluciones y períodos de anarquía, en todos los casos originadas por ideas, intereses y ambiciones que se proyectaron en actitudes, proyectos y acciones unilaterales del "todo o nada".

$Y$ es que todas las transformaciones, incluso las más profundas, si buscan ser duraderas, no pueden — sino a un altísimo costo — imponerse por la vía rupturista, aprovechando una circunstancia momentánea de predominio político... En cambio, pueden encontrar por la vía de la innovación o de la 'actualización-tradicional-proyectiva' y acordada un mucho mejor cauce para recorrer su itinerario. Pero para ello se requiere, tanto la asimilación de nuestras historias — sin masoquismos, complejos ni rencores- como la comprensión de las circunstancias presentes para trazar y recorrer el proyecto de un futuro mejor, siendo precisamente el porvenir su parte esencial.

Así pues, además de nuestra historia y cultura compartidas, lo que debe unirnos como nación y como comunidad internacional, como patria grande, es pues un proyecto común de futuro.

Futuro que puede construirse también considerando y aprovechando otras experiencias actuales, como por ejemplo la europea, para preguntarnos así: ¿Cómo fue posible una alianza franco-alemana tras la Segunda Guerra Mundial? ¿Cómo ha conseguido la Europa de los seis de la década de los 1950’s integrar a 28 países? ¿De qué manera transitó de una unión aduanera a un mercado común, a una unión monetaria y luego a una integración completa? ¿Qué beneficios e inconvenientes ha traído la Unión Europea al ciudadano común?

Futuro que debe considerar también nuestra propia realidad nacional y hemisférica contemporánea, preguntándonos: ¿Hacia dónde se dirige la política exterior de los Estados Unidos de Norteamérica? ¿Qué posición geopolítica tiene México en el contexto del nuevo Tratado aún pendiente de ratificación con Canadá y con los Estados Unidos y de sus demás tratados comerciales con otros países de América Latina, con la Unión Europea y con Asia? ¿Qué podemos aprender de la coyuntura actual de Venezuela? ¿Qué papel ha jugado y puede desempeñar la OEA? ¿Qué tan bien ha funcionado el Sistema Interamericano de Derechos Humanos? ¿Qué proyección se le ha dado a las Cumbres Iberoamericanas? ¿Hacia dónde debe dirigirse la Alianza del Pacífico?

Lo cierto es que a más de doscientos años de la propuesta de Talamantes de conformar "un espíritu de unión”, la integración latinoamericana sigue siendo más un anhelo — cuando mucho un proyecto inacabado y pendien- 
te- que una realidad. En efecto, a diferencia por ejemplo de la Unión Europea, Iberoamérica, Latinoamérica -0 , más precisamente, Indo-AfroIberoamérica, según la expresión acuñada por Fuentes-, sigue siendo una realidad a medias que no termina de concretarse.

Y es que a pesar de la crisis financiera global de 2007, del Brexit de 2016 - todavía pendiente de concretarse- y de los dolorosos ajustes financieros - con impacto sobre todo en el corto plazo sobre los países mediterráneos-, puede afirmarse que la Unión Europea ha asumido un destacado liderazgo en el ámbito internacional, promoviendo la complementación económica de su producción y consumo, liberalizando la circulación de los factores de la producción (bienes, servicios, capitales y personas), compensando asimetrías locales o sectoriales mediante fondos estructurales, aumentando su productividad mediante la operación a escalas, creando riqueza y empleos, promoviendo la educación y la movilidad laboral y, sobre todo, elevando la calidad de vida de los europeos, creando además un espacio común de seguridad, democracia, derechos humanos y libre tránsito de residentes.

Europa es una realidad — si se quiere imperfecta, pero tangible y benéfica, sin ser tampoco la panacea-, mientras que Latinoamérica sigue siendo una aspiración pendiente. Por eso, en los términos de los análisis geopolíticos y económicos críticos, Europa es centro, mientras que Latinoamérica es periferia.

Más allá del peso individual de sus países, la Unión Europea es un auténtico hegemón y un protagonista, en lo político y en lo económico, mientras que las naciones latinoamericanas, aisladas, pesan poco en el contexto internacional y desperdician el potencial - económico y de desarrollo socialque tendrían con sus capacidades y presencia sumadas.

Hoy por hoy nuestro continente, con un mapa entrecruzado por organismos y tratados que yuxtaponen los más diversos esquemas de cooperación internacional (desde uniones aduaneras hasta mercados comunes, pasando por tratados de libre comercio, organismos internacionales, y grupos de concertación política), abrazando en lo geográfico, económico y cultural distintos espacios que van de lo Panamericano a lo Caribeño, pasando por el Pacífico, Norteamérica y Centroamérica no acaba de consolidarse en el actual contexto de la globalización regionalizada.

Si quisiéramos dibujar un cuadro impresionista —en pocas y breves pinceladas - del estado actual de la cuestión, diríamos que nuestro continente se encuentra recorrido por: a) una organización panamericana regional hemisférica (la OEA y el SIDH específicamente latinoamericano), b) varios proyectos truncos a nivel latinoamericano (como CEPAL, SELA y ALADI), c) una proliferación de subregiones (Centroamérica, el Caribe, los Andes, Sudamérica, Asia-Pacífico y Norteamérica) y d) un proyecto cultural iberoamericano. 
Y no deja de ser lamentable, pues el balance económico es muy pobre si se contrasta el porcentaje del comercio intrarregional europeo, del 64\%, o del asiático, que alcanza el 50\%, con el magro $16 \%$ que representa el total del comercio interno dentro de la subregión latinoamericana. Dicho balance nos permite dimensionar la medida del desperdicio y de la oportunidad.

En efecto, si se considera que América Latina tiene una extensión territorial conjunta de más de 22 millones de kilómetros cuadrados, que cuenta con una población de alrededor de los 658 millones de habitantes, un PIB nominal de aproximadamente 5.9 billones de dólares y reúne en su seno algunas de las mayores economías del planeta — como Brasil, la número 8, México, la número 15 y Argentina la número 27-, puede apreciarse cómo la sola integración subregional Latinoamericana daría lugar a la formación de la cuarta potencia económica a nivel mundial — tan sólo después de China, la Unión Europea y Estados Unidos, la tercera potencia en materia de energía eléctrica y el mayor productor de alimentos del mundo.

Lo anterior sin contar la importante riqueza petrolera de trece países - entre los que destacan Venezuela, Brasil y México—, la abundancia minera de Chile (cobre), Perú (plata) y de Bolivia, Brasil, Argentina y México (minería de conjunto), las llanuras para el cultivo y la ganadería, las costas para la pesca y la inmensa biodiversidad del continente.

Pero a la anterior riqueza material habría que sumarle el hecho, de que desde un punto de vista geográfico, América Latina - y específicamente Iberoamérica- es la mayor continuidad histórico-cultural del mundo, donde más allá de su riqueza policromática —plurinacional, pluriétnica y pluricultural- constituye la región más homogénea de cuántas aspiran a la integración regional.

Ahí está la mejor parte del legado y proyecto pendientes de Talamantes, que es también el de Bolívar y Miranda, Bello, Sarmiento y Alberdi; Portales, Alamán, Bilbao y Torres Caicedo; Martí, Rodó, a Henríquez Ureña, Vaz Ferreira, Caso y Vasconcelos; Reyes, Gaos, y, junto con ellos, otros tantos intelectuales más recientes, que directa o indirectamente han contribuido a la configuración de un pensamiento latinoamericano, como Uranga, O’Gorman, Larroyo, Kusch, Caturelli, Korn, Ribeiro, Fuentes, Romero, García Márquez, Paz, Salazar Bondy, Arguedas, Picón Salas, Ardao, Villoro, Roig, Cerutti, Bosch, Miró Quesada, Mariátegui, Zea, Ribeiro, Haya de la Torre, Abellán, Magallón, Dussel, Cerutti, Scannone, FornetBetancourt, Echeverría, Castro-Gómez y tantos y tantos más que sería imposible citar sin prolongarnos en exceso, pero que en justicia merecen y deben ser recordados, al igual que Talamantes.

En todo caso, cualquier intento de integración americana tendría que partir, nuevamente, del planteamiento de los conceptos que recorren el pensamiento de Talamantes: nación, soberanía, independencia y constitución, si 
bien en nuestro tiempo tendrían que reflexionarse a nivel internacional y supranacional y abarcar, además de las cuestiones propias de nuestra región, aquéllas que atañen a la arquitectura comercial y financiera internacional y que requerirían del rediseño, por lo menos, de la ONU, de la OCDE, del Banco Mundial y del Fondo Monetario Internacional, para frenar y compensar las desigualdades estructurales, industriales, comerciales y financieras de la economía global, que han sumido a Latinoamérica a la condición de 'periferia' o 'semiperiferia'.

Finalmente, un importante aspecto a destacar del legado de Talamantes tiene que ver con su participación indirecta, desde la sociedad, reflexionando, proponiendo y hasta empujando sus proyectos. Y ése es un aspecto muy importante si se considera, como lo hacen algunos, que en la Iberoamérica o Latinoamérica de hoy —al igual, lamentablemente, que en la Europa y, en general, en el mundo de nuestros días - no se vislumbran liderazgos como los que fueron capaces de cimentar la Unión Europea. Hombres de la talla, visión y voluntad de Winston Churchill, Jean Monnet, Konrad Adenauer, Alcide De Gasperi, Paul Henri-Spaak, León Blum, Robert Schumann (verdaderos héroes de la Europa actual). Pero, aun suscribiendo dicha perspectiva, quizás el proceso de integración americana pueda y deba realizarse de manera precisamente inversa a como se configuró la Unión Europea.

En efecto, si en Europa fue la visión y voluntad de la sociedad política la que impuso un dinamismo que después siguió la sociedad civil, acaso en nuestra América - itanto mejor! - pueda ser la sociedad civil la que promueva, desde las letras, las ciencias sociales, las humanidades, las organizaciones no gubernamentales, la academia, las universidades, las sociedades científicas y profesionales, los medios de comunicación. La idea, la aspiración, el plan maestro, el proyecto concreto para lograr la - tan lamentablemente pospuesta, tan esperanzadoramente ansiada- Integración Latinoamericana.

Y ahí está, pendiente, el testimonio, legado y proyecto de Talamantes, tras dos siglos de abandono, aunque todavía presente, esperando que llegue el día de realización. Ojalá que sea pronto. Muchas gracias, A.M.D.G., 2019.

\section{BIBLIOHEMEROGRAFÍA}

Abellán, José Luis. La idea de América. Origen y Evolución, Madrid, Iberoamericana-Vervuert, 2009.

Alarcón Bejarano, Eleuterio O. de M., “Fray Melchor Talamantes, ideólogo y prócer de la independencia americana” en Analecta Mercedaria, núm. 13 (1994). Roma, Instituti Historici Ordinis de Mercede, 1998.

Aninno, Antonio (coord.), La revolución novohispana, 1808-1821, México, CIDE, FCE, Conaculta, INHERM, 2010. 
Aparicio Quispe, Severo, O. de M. (ed.), Epistolario de Fray Melchor Talamantes Baeza, O. de M., sobre la delimitación de las provincias de Luisiana y Texas (1807-1808), estudio preliminar de Teodoro Hampe Martínez, Lima, Provincia Mercedaria del Perú, 2009.

Aparicio Quispe, Severo, O. de M., "Fray Melchor de Talamentes, O. de M., precursor de la Independencia de México”, en Revista Peruana de Historia Eclesiástica, 1995.

Ávila, Alfredo y Pedro Pérez Herrero (comps.), Las experiencias de 1808 en Iberoamérica, México, Universidad Nacional Autónoma de México y Universidad de Alcalá de Henares, 2008.

Barrios, Feliciano (coord.), El Gobierno de un Mundo. Virreinatos y Audiencias en la América Hispánica, Cuenca, Ediciones de la Universidad Castilla-La Mancha, 2004.

Beorlegui, Carlos, Historia del Pensamiento Filosófico Latinoamericano. Una búsqueda incesante de la Identidad, 3a. edición, Bilbao, Universidad de Deusto, 2010.

Beuchot, Mauricio, Historia del Filosofía en el México Colonial, Barcelona, Editorial Herder, 1996.

Beuchot, Mauricio, Tratado de Hermenéutica Analógica. Hacia un nuevo modelo de interpretación, México, Facultad de Filosofía y Letras de la Universidad Nacional Autónoma de México e Itaca, 2000.

Brading, David, Orbe Indiano. De la monarquía católica a la República criolla. 1492-1867, trad. de Juan José Utrilla, México, FCE, 1991.

Breña, Roberto, El primer liberalismo español y los procesos de emancipación de América, 1808-1824. Una revisión historiográfica del liberalismo hispánico. México, El Colegio de México, 2006.

Comisión Económica para América Latina y el Caribe (CEPAL), Estudio Económico de América Latina y el Caribe 2018, Santiago, Naciones Unidas, 2018.

Chiaramonte, José Carlos, "Fundamentos iusnaturalistas de los movimientos de Independencia”, en María Terán y José Antonio Serrano Ortega (eds.), Las Guerras de Independencia en la América Española. México, El Colegio de Michoacán-Universidad Michoacana de San Nicolás de Hidalgo-INAH, Conaculta, 2002.

Chust, Manuel, 1808. La eclosión juntera en el mundo hispano, México, FCE, 2007.

De la Torre Villar, Ernesto, La independencia de México, México, FCE-Fundación Mapfre, 1992.

Dussel, Enrique Eduardo Mendieta y Carmen Bohórquez (eds.), El Pensamiento Filosófico Latinoamericano, del Caribe y “Latino” (1300-2000). Historia, corrientes, temas y filósofos, CREFAL-Siglo Veintiuno Editores, 2009.

Fuentes, Carlos, El espejo enterrado, México, FCE, 1992.

Galeana, Patricia (coord.), La Consumación de la Independencia. México, 2 tomos, Archivo General de la Nación, 1999. 
Gallegos Rocafull, José M., La Doctrina Política del P. Francisco Suárez, México, Editorial Jus, 1948.

García I, Genaro, Documentos Históricos Mexicanos, Edición facsimilar de la obra conmemorativa del primer centenario de la Independencia de México, publicada por la Secretaría de Instrucción Pública y Bellas Artes en 1910, México, Secretaría de Educación Pública, 1985.

__ El plan de independencia de la Nueva España en 1808, México, Imprenta del Museo Nacional, 1903.

González Obregón, Luis (autor y comp.), Fray Melchor de Talamantes. Biografía y escritos póstumos, México, Secretaría de Relaciones Exteriores, 1909; reeditada como Fray Melchor de Talamantes. Argumentos a favor de la Independencia de México (presentación, bibliografía de Luis González y textos), México, Ediciones del Centro de Documentación Política, 1979.

Guedea, Virginia (coord.), La Independencia de México y el Proceso Autonomista Novohispano 1808-1824, México, Universidad Nacional Autónoma de México e Instituto Mora. 2001.

Guerra, François-Xavier (dir.), Las Revoluciones Hispánicas: Independencias Americanas y Liberalismo Español, Madrid, Editorial Complutense, 1995.

Halperin Donghi, Tulio, Historia contemporánea de América Latina. Madrid. Alianza Editorial, 2008.

Hampe Martínez, Teodoro, "Fray Melchor de Talamantes y Baeza, Mercedario Limeño, Protomártir de la Independencia de México”, en Historia Comparada de las Américas: sus procesos independentistas, México, Senado de la República, 2010.

Henriod de los Ríos, Carlos, “Talamantes, Precursor de la Independencia de América”, Discurso de Incorporación al Centro de Estudios Histórico-Militares del Perú, Lima, 2001.

Hernández Sánchez-Barba, Mario, Las independencias americanas (1767-1878). Génesis de la descolonización, Madrid, Universidad Francisco de Vitoria. 2009.

Hernández Silva, Héctor Cuauhtémoc y Juan Manuel Pérez Zevallos (eds.), Fray Melchor Talamantes. Escritos póstumos 1808, México, CIESAS, UAB, UAM, GDF, 2009.

Herrejón Peredo, Carlos, Del sermón al discurso cívico. México, 1760-1834, México, El Colegio de Michoacán-El Colegio de México, 2003.

Herrera Peña, José, Soberanía, Representación Nacional e Independencia en 1808, México, Senado de la República, 2010.

Lafuente Ferrari, Enrique, El Virrey Iturrigaray y los orígenes de la Independencia de México, Madrid, Consejo Superior de Investigaciones Científicas, 1941.

Lynch John, Las Revoluciones Hispanoamericanas. 1808-1826, trad. Javier Alfaya y Bárbara McShane, Barcelona, Editorial Ariel, 2010. 
Mazín, Óscar, Iberoamérica. Del descubrimiento a la independencia, México, El Colegio de México, 2007.

Medina, José Toribio, Historia del Tribunal del Santo Oficio de la Inquisición en México, 2a. edición ampliada por Julio Jiménez Rueda, México, Ediciones Fuente Cultural, 1952.

Miranda, José, Las ideas y las instituciones políticas mexicanas, 2a. edición, México, Instituto de Investigaciones Jurídicas, unAM, 1978.

Ochoa Ventura, Miguel, O. de M., Fray Melchor Talamantes y Baeza. Religioso Mercedario Limeño, Lima, Provincia Mercedaria del Perú, Talleres Gráficos, 2009.

Ortega y Gasset, José, Obras, Madrid, Espasa Calpe, 1932.

Pampillo Baliño, Juan Pablo, El Primer Constitucionalista de México. Talamantes: ideología y proyecto para la América Septentrional, México, Escuela Libre de Derecho-Editorial Porrúa, 2010.

Pampillo Baliño, Juan Pablo, Nuevas reflexiones sobre la Integración Jurídica Latinoamericana, Lima, Editorial Rimay, 2019.

Portillo Valdés, José María, Crisis atlántica: Autonomía e independencia en la crisis de la Monarquía Hispana, Madrid, Marcial Pons, 2006.

Puga y Acal, Manuel, Verdad y Talamantes, primeros mártires de la independencia, México, Tipografía de El Progreso Latino, 1908.

Rodríguez Braun, Carlos, La cuestión colonial y la economía clásica. De Adam Smith y Jeremy Bentham a Karl Marx, Madrid, Alianza Editorial, 1989.

Rodríguez Garza, Javier y Lucino Gutiérrez Herrera, Ilustración Española, Reformas Borbónicas y Liberalismo Temprano en México, México, UAM, 1992.

Romero del Valle, Emilia, "Fray Melchor de Talamantes”, en Historia Mexicana. Revista trimestral, El Colegio de México, vol. XI, México, 1961.

, “Talamantes, prócer de America (1765-1809): su vida, su obra y su bibliografía”, en Fénix. Revista de la Biblioteca Nacional del Perú, Lima, 1944.

Rosas Cuadros, Emilio E., Precursores peruanos que contribuyeron a la independencia de los pueblos de América, 2a. edición, Lima, Ediciones Rosas, 2002.

Salmerón, Fernando, Filosofía e historia de las ideas en México y América Latina. México, UNAM-IIF, 2007.

Soberanes Fernández, José Luis, El Pensamiento Constitucional de la Independencia, México, Editorial Porrúa-unAm, 2012.

Stoetzer, O. Carlos, Las raíces escolásticas de la emancipación de la América Española, Madrid, Centro de Estudios Constitucionales, 1982.

Tena Ramírez, Felipe, El Ideario Político-Constitucional de los Criollos Mexicanos de 1808, México, Escuela Libre de Derecho, Editorial Porrúa, INEHRM, 2010.

VV.AA., Ideas en torno de Latinoamérica. 2 volúmenes, UNAM y Unión de Universidades de América Latina, 1986.

Presencia de Rousseau. A los 250 años de su nacimiento y a los dos siglos de la aparición del Emilio y El contrato social, México, UnAM, 1962. 
Villoro, Luis, El proceso ideológico de la Revolución de Independencia, México, UNAM, 1983.

Zea, Leopoldo, Dos etapas del pensamiento en Hispanoamérica, El Colegio de México, 1949.

\section{Archivos}

Archivo Arzobispal de Lima, Perú.

Archivo General de la Nación, México.

Archivo General de Indias, Sevilla.

Archivo Mercedario de la Provincia de Lima, Perú.

Archivo de la Universidad de Texas-Stephens Collection of Manuscripts. 